\title{
THE NATIONAL ACADEMIES
}

Advisers to the Nation on Science, Engineering, and Medicine

Division on Engineering and Physical Sciences

500 Fifth Street, NW

Board on Physics and Astronomy

Washington, DC 20001

Rare Isotope Science Assessment Committee

Phone: 2023343520

Fax: 2023343575

E-mail: bpa@nas.edu

www.nas.edu/bpa

May 22, 2007

\section{Final Report to the Department of Energy}

\section{Project Identification}

Project Title: $\quad$ Rare Isotope Science Assessment Committee

Agency Award No.: $\quad$ DE-FG02-05ER-41401

Reporting Period: $\quad$ August 15, 2005 to , 2007

\section{Summary}

The Rare Isotope Science Assessment Committee (RISAC) was convened by the National Research Council in response to an informal request from the DOE's Office of Nuclear Physics and the White House Office of Management and Budget. The charge to the committee is to examine and assess the broader scientific and international contexts of a U.S.-based rare-isotope facility. The committee met for the first time on December 16-17, 2005, in Washington, DC, and held three subsequent meetings. The committee's final report was publicly released in unedited, prepublication form on Friday, December 8, 2006. The report was published in full-color by the National Academies Press in April 2007. Copies of the report were distributed to key decision makers and stakeholders around the world.

\section{Recent Activities}

\section{Project Initiation}

The Rare Isotope Science Assessment Committee (RISAC) was convened by the National Research Council in response to an informal request from the DOE's Office of Nuclear Physics and the White House Office of Management and Budget.

The committee will define a scientific agenda for a U.S. domestic rare-isotope facility, taking into account current government plans. In preparing its report, the committee will address the role that such a facility could play in the future of nuclear physics, considering the field broadly, but placing emphasis on its potential scientific impact on nuclear structure, nuclear astrophysics, fundamental symmetries, stockpile stewardship and other national security areas, and future availability of scientific and technical personnel. The need for such a facility will be addressed in the context of international efforts in this area.

In particular, the committee will address the following questions:

- What science should be addressed by a rare isotope facility and what is its importance in the overall context of research in nuclear physics and physics in general? 
- What are the capabilities of other facilities, existing and planned, domestic and abroad, to address the science agenda? What scientific role could be played by a domestic rare-isotope facility that is complementary to existing and planned facilities at home and elsewhere?

- What are the benefits to other fields of science and to society of establishing such a facility in the United States?

To assemble the committee, the BPA worked with the American Physical Society's Division of Nuclear Physics to solicit nominations for membership from the broader community. More than 50 nominations were received. A slate of 18 members was composed with two co-chairs, one from within nuclear physics, and one with a broader perspective on nuclear science and engineering and science policy (see enclosure for committee membership roster). The chair of the National Research Council, made the final committee appointment decisions on November 7, 2005.

\section{Meetings}

At its first meeting, held December 16-17, 2005, in Washington, D.C, the committee discussed its task and heard public presentations. Invited testimony at the first meeting included remarks from the federal agency stewards of the field of nuclear physics (DOE Office of Nuclear Physics and NSF Division of Physics) and discussion of the broader context for the physical sciences by OMB and OSTP representatives. The committee also heard from the chair of the previous Nuclear Science Advisory Committee's long-rang plan, which placed the Rare Isotope Accelerator in the framework of the longerrange outlook for the field. With help from the American Physical Society's Division of Nuclear Physics, the committee convened an extended public-comment session where representatives from the broader community where invited to address the committee on any of the issues relating to the task. Finally, the committee heard testimony from the chair of a recent Nuclear Science Advisory Committee subpanel that compared plans for the Rare Isotope Accelerator and the upgrade of a project at GSI in Darmstadt, Germany. In the remaining hours of the meeting, the committee discussed elements of the scientific motivation, framed its work plan, and made plans for its next meetings.

At its second meeting, held February 11-12, 2006, in Irvine, California, the committee entertained additional public presentations on the specific science case for a rare-isotope facility. In general terms, the committee worked on the following topics:

- Interim report. Without formally deciding for or against the production of an interim report, the committee agreed to continue developing ideas for it; a third meeting in March 2006 would be largely focused on its preparation. [NOTE: Since this meeting, the informal request for an interim report has been retracted and it will no longer be pursued.]

- Plans for the next meeting. Because of the developing budget-making process, the committee agreed to hear again from agency and budget officials about the outlook for nuclear physics. The committee also agreed to learn more about options for descoping or staging the construction of RIA to better understand the potential synergies of the different subsystems.

- Writing assignments. Individuals from the committee expert in selected areas agreed to review, critique, and propose improvements to the different sections of the 'RIA science case' white paper prepared for this meeting.

At its third meeting, held March 12-13, in Washington, DC, the committee discussed the issues further. Dennis Kovar and Joel Parriott confirmed that the facility-concept-formerly-known-as-RIA is no longer viable and any DOE construction initiative on a rare-isotope facility is likely to be delayed until 2011 at the earliest. They explained that there will be an increased emphasis on U.S. participation in international activities during the interim. The charge to the committee was slightly revised to reflect these changes in 
context. To assess and eventually make the case for a domestic rare-isotope facility, the committee elected to identify a handful of the most compelling science experiments/questions and then analyze them in terms of world-wide capability for making progress (taking into account existing and planned facilities).

Committee member writing assignments were also reviewed and updated.

The committee met for the fourth time on July 14-15, 2006, at TRIUMF in Vancouver, British Columbia. The meeting was devoted entirely to closed-session discussions save for a presentation by the director of TRIUMF about the nuclear physics programs and plans at the laboratory and a tour of the facilities. The committee reviewed progress on the draft components of its final report, discussed tentative findings and recommendations, and laid out the final phase of its work designed to deliver a final report in October 2006.

Since the fourth meeting, the committee completed its report, responded to review comments, and publicly released the final report in December 2006.

\section{Report Findings}

\section{Background}

Over ten years ago, U.S. nuclear scientists proposed construction of a new rare isotope accelerator in the United States. Such a facility would enable experiments to elucidate the structure of exotic, unstable nuclei and provide critical information needed to explain nuclear abundances in the universe. Studies by the NSFDOE Nuclear Science Advisory Committee supported this proposal-initially termed the Rare Isotope Accelerator. In 2005, DOE and NSF, seeking an independent scientific assessment, asked the NRC to define the science agenda for a next-generation U.S. Facility for Rare Isotope Beams (FRIB). As the study began, DOE announced that the budget for what was then the RIA should be reduced about in half. The study focused on an evaluation of the science that could be accomplished with a facility reduced in scope. The revised charge also directed the NRC to evaluate the scientific impact of a FRIB in the overall context of the national and international nuclear physics programs. Finally, the NRC was not asked to give advice on whether such a facility should be constructed.

\section{Findings and Conclusions}

According to current DOE plans, a FRIB facility might not begin operations until 2016. Nevertheless, most of the major technical issues for building this facility appear to be well in hand. Further a next generation radioactive beam facility of the type embodied in the U.S. FRIB concept represents a unique opportunity to explore the nature of nuclei under extreme conditions and to develop a more quantitatively robust characterization of nuclear structure by exploring new forms of nuclear matter.

A FRIB could impact the study of the origin of the elements and the evolution of the cosmos. Several key science drivers are apparent:

- Nuclear structure. A FRIB would offer a laboratory for exploring the limits of nuclear existence and identifying new phenomena, with the possibility that a more broadly applicable theory of nuclei will emerge.

- Nuclear astrophysics. A FRIB would lead to a better understanding of key issues by creating exotic nuclei that, until now, have existed only in nature's most spectacular explosion, the supernova. It would offer new glimpses into the origin of the elements.

- Fundamental symmetries of nature. Experiments addressing questions of the fundamental symmetries of nature will similarly be conducted at a FRIB through the creation and study of certain exotic isotopes. 
Nuclear structure and nuclear astrophysics constitute a vital component of the nuclear science portfolio in the United States. Moreover, nuclear-structure-related research provides the scientific basis for important advances in medical research, national security, energy production, and industrial processing. Failure to pursue a U.S.-FRIB would likely lead to a forfeiture of U.S. leadership in nuclear-structure-related physics and would curtail the training of future U.S. nuclear scientists.

A U.S. facility for rare-isotope beams of the kind described to by DOE would be complementary to existing and planned international efforts, particularly if based on a heavy-ion linear accelerator. With such a facility, the United States would be a partner among equals in the exploration of the world-leading scientific thrusts listed above.

The science addressed by a rare-isotope facility, most likely based on a heavy-ion driver using a linear accelerator, should be a high priority for the United States. The facility for rare-isotope beams envisaged for the United States would provide capabilities unmatched elsewhere that would help to provide answers to the key science topics outlined above.

\section{Outreach}

The committee has made significant efforts to engage and involve the broader community. The Division of Nuclear Physics of the American Physical Society helped organize a 2.5-hour public-comment session at the committee's first meeting where representatives of the different facilities, users' groups, and the broader community were invited to address the committee. The committee also maintains a public website (URL http://www7.nationalacademies.org/bpa/RISAC.html) with announcements about meetings, copies of presentations and comments made to the committee, and a standing call for community input.

The committee's final report was made publicly available on Friday, December 8, 2006, on the National Academies' website, in unedited, prepublication form. Advance courtesy briefings were provide to DOE, NSF, OSTP, OMB, and selected offices in Congress. A public presentation of the report was made in Chicago, Illinois, at a meeting of the NSF/DOE Nuclear Science Advisory Committee's Task Force on Rare-Isotope Beams. An article covering the event was published in the Chicago Tribune on Saturday, December 9, 2006.

\section{Attachments}

- Committee membership roster

- Meeting agendas (4)

- Executive Summary

- Article from the Chicago Tribune

- Article from Science magazine

END. 


\section{THE NATIONAL ACADEMIES}

Advisers to the Nation on Science, Engineering, and Medicine

\section{Rare Isotope Science Assessment Committee (RIA)} Terms expire on October 31, 2007

\author{
John F. Ahearne, Co-Chair \\ Director, Ethics Program \\ Sigma Xi, and Duke University \\ P.O. Box 13975 \\ Research Triangle Park, NC 27709 \\ Tel: 919/547-5213 Fax: 919/549-0090 \\ E-mail: ahearne@sigmaxi.org
}

\section{Stuart J. Freedman Co-Chair}

Professor of Physics

University of California at Berkeley

Department of Physics

366 LeConte Hall

Berkeley, CA 94720

Tel: 510/486-7850 Fax: 510/486-6738

E-mail: sjfreedman@lbl.gov

\section{Ricardo Alarcon}

Professor of Physics

Arizona State University

Mail Code 1504

Tempe, AZ 85287

Tel: 480/965-8549 Fax: 480/965-7954

E-mail: ricardo.alarcon@asu.edu

\section{Peter Braun-Munzinger}

Divison Head

Gesellschaft fur Schwerionenforschung (GSI)

Gesellschaft fur Schwerionenforschung $\mathrm{mbH}$

Planckstrasse 1

64291 Darmstadt

GERMANY.

Tel: 4-6159-71-2760 Fax: 49-6159-71-2785

E-mail: p.braun-munzinger@gsi.de

Assistant : Sandra Schecker

\section{Adam S. Burrows}

Professor of Physics and Astronomy

Steward Observatory

University of Arizona

Tucson, AZ 85721

Tel: 520/621-1795 Fax: 520/621-1532

E-mail: burrows@as.arizona.edu

\author{
Richard F. Casten \\ Professor of Physics and Director, \\ Wright Nuclear Structure \\ Yale University \\ New Haven, CT 06520-8124 \\ Tel: 203/432-6174 Fax: 203/432-3522 \\ E-mail: rick@riviera.physics.yale.edu \\ Assistant: Mary Anne Schulz \\ E-mail: maryanne@mirage.physics.yale.edu

\section{Yanglai Cho} \\ Retired, Argonne National Laboratory \\ 105078 Leonard Drive \\ Burr Ridge, IL 60527-6031 \\ Tel: 630/655-8804 \\ E-mail: ycho@anl.gov

\section{Gerald T. Garvey} \\ Senior Laboratory Fellow \\ Los Alamos National Laboratory \\ P.O. Box 1662 \\ Los Alamos, NM 87545 \\ Tel: 505/667-9497 Fax: 505/665-7920 \\ E-mail: garvey@lanl.gov

\section{Wick C. Haxton} \\ Director, Institute for Nuclear Theory \\ and Professor of Physics \\ University of Washington \\ University of Minnesota \\ Seattle, WA 98195 \\ Tel: 206/685-2397 Fax: 206/685-3730 \\ E-mail: haxton@phys.washington.edu \\ Assistant : Linda Vilett

\section{Robert L. Jaffe} \\ Jane and Otto Morningstar \\ Professor of Physics \\ Massachusetts Institute of Technology \\ Cambridge, MA 02139-4307 \\ Tel: 617/253-4858 Fax: 617/253-8674 \\ E-mail: jaffe@mit.edu
}

Noemie B. Koller 
Professor of Physics

Rutgers, The State University of New Jersey 136 Frelinghuysen Road

Serin W214

Piscataway, NJ 08554-8019

Tel: 732/445-2525 Fax: 732/445-4343

E-mail: nkoller@physics.rutgers.edu

\section{Stephen Libby}

Theory and Modeling Group Leader

Physics and Advanced Technologies

V Division

Lawrence Livermore National Laboratory

Livermore, CA 94550

Tel: 925/422-9785 Fax: 925/423-7228

E-mail: libby1@llnl.gov

Assistant: Stefanie Landes

E-mail: landes1@llnl.gov

\section{Shoji Nagamiya}

Director

Japan Proton Accelerator Research Complex

KEK, National Laboratory for High Energy

Physics Research

1-1 Oho, Tsukuba-shi

lbaraki-ken 305-0801

JAPAN

Tel: 81-298-64-5678 Fax: 81-298-64-5258

E-mail: shoji.nagamiya@kek.jp

\section{Witold (Witek) Nazarewicz}

Professor of Physics

University of Tennessee at Knoxville

505 Nielsen Physics Building

Knoxville, TN 37996

Tel: 865/974-4580 Fax: 865-974-7843

E-mail: witek@utk.edu

\section{Michael Romalis}

Professor of Physics

Princeton University

230 Jadwin Hall

Princeton, NJ 08540

Tel: 650/258-5586 Fax: 650/258-5586

E-mail: romalis@princeton.edu

\section{Paul Schmor}

Head, Isotope Accelerator and Separator Division
TRIUMF

University of British Columbia

4004 Wesbrook Mall

Vancouver, BC V6T2A3

CANADA

Tel: 604/222-7415 Fax: 604/222-1074

E-mail: schmor@triumf.ca

Michael C.F. Wiescher

Freimann Professor of Nuclear Physics

University of Notre Dame

2225 Nieuwland Science Hall

Notre Dame, IN 46556

Tel: 574/631-6788 Fax: 574/631-5952

E-mail: wiescher.1@nd.edu

\section{Stanford E. Woosley}

Professor of Astronomy and Astrophysics

University of California at Santa Cruz

Department of Astronomy and Astrophysics

Santa Cruz, CA 95064

Tel: 831/459-2976 Fax: 831/459-5265

E-mail:woosley@ucolick.org

\section{NRC Staff}

Donald C. Shapero, Director

E-mail: dshapero@nas.edu

Timothy I. Meyer, Senior Program Officer

E-mail: tmeyer@nas.edu

Pamela A. Lewis, Program Associate

Email: plewis@nas.edu

Board on Physics and Astronomy

The National Academies

$5005^{\text {th }}$ Street NW

M/S WS-922

Washington, DC 20001

Tel: 202-334-3520 Fax: 202-334-3575

E-mail: bpa@nas.edu 


\section{Rare Isotope Science Assessment Committee}

Keck Center of the National Academies, Room 203

500 Fifth Street, NW, Washington, DC 20001

Friday, December 16, 2005

\begin{tabular}{|c|c|c|}
\hline \multicolumn{3}{|c|}{ Closed Session } \\
\hline $7: 30 \mathrm{am}$ & Breakfast & Keck 203 \\
\hline 8:00 am & Welcome and plans for the meeting & $\begin{array}{l}\text { J. Ahearne, Co-chair } \\
\text { S. Freedman, Co-chair }\end{array}$ \\
\hline 8:15 am & Committee balance and composition discussion & $\begin{array}{l}\text { D. Shapero, Director } \\
\text { Board on Physics \& Astronomy }\end{array}$ \\
\hline 9:15 am & Introduction to the NRC & $\begin{array}{l}\text { T.I. Meyer, Sr. Prog. Officer } \\
\text { Board on Physics \& Astronomy }\end{array}$ \\
\hline 9:30 am & \multicolumn{2}{|l|}{ General discussion } \\
\hline 9:45 am & \multicolumn{2}{|l|}{ Break } \\
\hline \multicolumn{3}{|c|}{ OPEN SESSION } \\
\hline 10:00 am & Perspectives from DOE I Nuclear Physics & $\begin{array}{l}\text { D. Kovar, Assoc Director } \\
\text { DOE Office of Nuclear Physics }\end{array}$ \\
\hline 10:30 am & Perspectives from NSF I Physics & $\begin{array}{l}\text { J. Dehmer, Director } \\
\text { NSF Division of Physics }\end{array}$ \\
\hline 11:00 am & Perspectives from OMB & $\begin{array}{l}\text { J. Parriott, Budget Examiner } \\
\text { Office of Management \& Budget }\end{array}$ \\
\hline $11: 30 \mathrm{pm}$ & General discussion & \\
\hline $12: 00 \mathrm{pm}$ & Lunch & (Committee in Keck 206) \\
\hline $1: 00 \mathrm{pm}$ & Perspectives from OSTP & $\begin{array}{l}\text { R. Dimeo, Acting Asst Dir } \\
\text { Physical Sciences and } \\
\text { Engineering, OSTP }\end{array}$ \\
\hline $1: 30 \mathrm{pm}$ & $\begin{array}{r}\text { Nuclear physics context of rare isotope science } \\
\text { NSAC Long-Range Planning report (2002) }\end{array}$ & $\begin{array}{l}\text { J. Symons, Chair } \\
\text { Lawrence Berkeley Nat'l Lab }\end{array}$ \\
\hline $2: 15 \mathrm{pm}$ & Perspectives from Capitol Hill & $\begin{array}{l}\text { M. Holland, Chairman's Staff } \\
\text { House Science Committee }\end{array}$ \\
\hline $2: 45 \mathrm{pm}$ & General discussion & \\
\hline $3: 15 \mathrm{pm}$ & Break & \\
\hline 3:30 pm & Public comments from user groups & \\
\hline $4: 30 \mathrm{pm}$ & Public comments from major facilities & \\
\hline
\end{tabular}




\begin{tabular}{|l|ll|}
\hline $5: 30 \mathrm{pm}$ & Other public comments & \\
\hline $6: 00 \mathrm{pm}$ & Adjourn & \\
\hline 7:00 pm & Committee dinner & $\begin{array}{l}\text { Oya Restaurant } \\
\text { 777 9th St. NW } \\
\text { Washington, DC 20001 }\end{array}$ \\
\hline
\end{tabular}

Saturday, December 17, 2005

\begin{tabular}{|c|c|c|}
\hline \multicolumn{3}{|c|}{ OPEN SESSION } \\
\hline 8:00 am & Breakfast & Keck 203 \\
\hline $8: 30 \mathrm{am}$ & $\begin{array}{l}\text { International context of rare isotope science } \\
\text { NSAC RIA/GSI comparison report (2004) }\end{array}$ & $\begin{array}{l}\text { P. Bond, Chair } \\
\text { Brookhaven Nat'l Lab }\end{array}$ \\
\hline 9:00 am & \multicolumn{2}{|l|}{ Discussion } \\
\hline \multicolumn{3}{|c|}{ CLOSED SESSION } \\
\hline 9:45 am & Initial impressions & J. Ahearne, S. Freedman \\
\hline 10:30 am & $\begin{array}{l}\text { Discussion of work plan } \\
\text { Proposed structure of the report } \\
\text { Proposed data-gathering } \\
\text { Proposed working groups } \\
\text { Plans for the next meeting }\end{array}$ & \\
\hline $12: 30 \mathrm{pm}$ & Lunch & \\
\hline $1: 30 \mathrm{pm}$ & Adjourn & \\
\hline
\end{tabular}




\section{THE NATIONAL ACADEMIES}

Advisers to the Nation on Science, Engineering, and Medicine

\section{Rare Isotope Science Assessment Committee \\ Beckman Center of the National Academies, Board Room \\ 100 Academy, Irvine, CA 92612}

\section{Saturday, February 11, 2006}

\begin{tabular}{|c|c|c|}
\hline $7: 45$ am & Carpool to conference center & Meet in hotel lobby \\
\hline 8:00 am & Breakfast & Dining Room \\
\hline \multicolumn{3}{|c|}{ CLOSED SESSION } \\
\hline 8:30 am & Welcome and plans for the meeting & $\begin{array}{l}\text { John Ahearne, Co-chair } \\
\text { Stuart Freedman, Co-chair }\end{array}$ \\
\hline $8: 45$ am & Initial discussions & \\
\hline 9:15 am & Break & \\
\hline \multicolumn{3}{|c|}{ OPEN SESSION } \\
\hline 9:30 am & Rare Isotope Science in the Context of Nuclear Physics & Rick Casten \\
\hline 10:00 am & Discussion & \\
\hline 10:30 am & The Rare Isotope Accelerator facility & Jerry Nolen \\
\hline $11: 00 \mathrm{am}$ & Discussion & \\
\hline $11: 45 \mathrm{am}$ & Lunch & Dining Room \\
\hline $12: 45 \mathrm{pm}$ & Rare Isotope Science: Nuclear Structure (experiment) & Brad Sherrill \\
\hline $1: 15 \mathrm{pm}$ & Rare Isotope Science: Nuclear Structure (theory) & Erich Ormand \\
\hline $1: 45 \mathrm{pm}$ & Discussion & \\
\hline $2: 15 \mathrm{pm}$ & Rare Isotope Science: Nuclear Astrophysics & Hendrik Schatz \\
\hline $2: 45 \mathrm{pm}$ & Rare Isotope Science: Astronomy \& Astrophysics & (John Cowan by phone) \\
\hline 3:15 pm & Discussion & \\
\hline 3:45 pm & Break & \\
\hline 4:00 pm & Rare Isotope Science: Stockpile Stewardship & David Crandall* \\
\hline
\end{tabular}




\begin{tabular}{|l|ll|} 
4:30 pm & Discussion & Guy Savard \\
$5: 00 \mathrm{pm}$ & Rare Isotope Science: Fundamental Symmetries & \\
\hline $5: 30 \mathrm{pm}$ & Discussion & Beckman Patio \\
\hline $6: 30 \mathrm{pm}$ & Adjourn & Bayside Restaurant \\
\hline $6: 45 \mathrm{pm}$ & Reception & Committee dinner (members and invited guests) \\
\hline
\end{tabular}

Sunday, February 12, 2006

\begin{tabular}{|c|c|c|}
\hline \multicolumn{3}{|c|}{ OPEN SESSION } \\
\hline $7: 45$ am & Carpool to conference center & Meet in hotel lobby \\
\hline 8:00 am & \multicolumn{2}{|l|}{ Breakfast } \\
\hline $8: 45 \mathrm{am}$ & Rare Isotope Science \& Technology: Addnl Applications & Larry Ahle \\
\hline $9: 15$ am & \multicolumn{2}{|l|}{ Discussion } \\
\hline $9: 45 \mathrm{am}$ & $\begin{array}{c}\text { Guidance for Implementing NSAC Long-Range Plan } \\
\text { Report of the NSAC subcommittee (2005) }\end{array}$ & Bob Tribble, Chair \\
\hline $10: 15$ am & \multicolumn{2}{|l|}{ Discussion } \\
\hline $10: 45$ am & \multicolumn{2}{|l|}{ Break } \\
\hline $11: 00 \mathrm{am}$ & Perspective on RIA and Nuclear Physics & $\begin{array}{l}\text { John Schiffer } \\
\text { Chair, } 1999 \text { NRC Survey }\end{array}$ \\
\hline $11: 30 \mathrm{am}$ & \multicolumn{2}{|l|}{ General Discussion } \\
\hline $12: 00 \mathrm{pm}$ & Lunch & Beckman Patio \\
\hline & \multicolumn{2}{|l|}{ CLOSED SESSION } \\
\hline $1: 00 \mathrm{pm}$ & \multicolumn{2}{|l|}{ Committee deliberations } \\
\hline 4:30 pm & Adjourn & \\
\hline
\end{tabular}




\section{THE NATIONAL ACADEMIES}

Advisers to the Nation on Science, Engineering, and Medicine Meeting

\section{Rare Isotope Science Assessment Committee}

\section{Keck Center of the National Academies, Room 101 500 Fifth St. N.W., Washington, DC}

\section{Sunday, March 12, 2006}

\begin{tabular}{|c|c|c|}
\hline 8:00 am & Breakfast & Keck 101 \\
\hline & CLosed Session & \\
\hline 8:30 am & Welcome and plans for the meeting & $\begin{array}{l}\text { John Ahearne, Co-chair } \\
\text { Stuart Freedman, Co-chair }\end{array}$ \\
\hline $8: 45$ am & Initial discussions & \\
\hline \multirow[t]{2}{*}{ 9:15 am } & Break & \\
\hline & OPEN SESSION & \\
\hline 9:30 am & New Developments in Planning for RIA & $\begin{array}{l}\text { Dennis Kovar } \\
\text { Joel Parriott }\end{array}$ \\
\hline 10:30 am & $\begin{array}{l}\text { Two Views on "The Elements of RIA: Options for Staging or } \\
\text { Descoping" }\end{array}$ & \\
\hline 10:30 am & The View from MSU & Konrad Gelbke \\
\hline 11:00 am & The View from Argonne & Don Geesaman \\
\hline 11:30 am & Discussion & \\
\hline 12:00 pm & Lunch & Keck 105 \\
\hline \multirow[t]{2}{*}{ 1:00 pm } & $\begin{array}{l}\text { The Role of Nuclear Structure in the Science Case for RIA } \\
\text { Discussion }\end{array}$ & Francesco lachello \\
\hline & CLosed Session & \\
\hline \multirow[t]{7}{*}{$2: 00 \mathrm{pm}$} & Elements of the Report & \\
\hline & Historical Context of Rare Isotope Science & Gerry Garvey and Bob Jaffe \\
\hline & Nuclear Structure & Gerry Garvey and Wick Haxton \\
\hline & Nuclear Astrophysics & $\begin{array}{l}\text { Stan Woosley, Michael Wiescher, } \\
\text { and Adam Burrows }\end{array}$ \\
\hline & Fundamental Symmetries & Michael Romalis \\
\hline & Broader Impacts \& Applications of RIA & Stephen Libby \\
\hline & International Programs & $\begin{array}{l}\text { Peter Braun-Munziger and Paul } \\
\text { Schmor }\end{array}$ \\
\hline 5:00 pm & $\begin{array}{l}\text { Roles of International Facilities in Meeting Rare Isotope } \\
\text { Research Needs over the Next Decade }\end{array}$ & Shoji Nagamiya \\
\hline 6:00 pm & General Discussion & \\
\hline $6: 30 \mathrm{pm}$ & Adjourn & \\
\hline $6: 45 \mathrm{pm}$ & Committee Dinner (members and invited guests) & Café Atlantico \\
\hline
\end{tabular}




\section{RISAC Meeting}

Monday, March 13, 2006

\begin{tabular}{|l|l|l|}
\hline & CLOSED SESSION & \\
\hline 8:00 am & Breakfast & \\
\hline 8:30 am & Convene & Stuart Freedman \\
\hline 8:30 am & What can be done with existing facilities and new facilities? & \\
\hline $\mathbf{9 : 1 5}$ & $\begin{array}{l}\text { What are the committee's current views--main conclusions } \\
\text { regarding RIA science }\end{array}$ & \\
\hline 10:00 am & Break & \\
\hline 10:30 am & $\begin{array}{l}\text { Further Discussion } \\
\text { Plans for completion of report } \\
\text { Further writing assignments }\end{array}$ & \\
\hline 11:45 am & Lunch & \\
\hline 1:00 pm & Adjourn & \\
\hline
\end{tabular}




\section{THE NATIONAL ACADEMIES}

Advisers to the Nation on Science, Engineering, and Medicine

\section{Rare Isotope Science Assessment Committee}

\section{TRIUMF, Auditorium}

Vancouver, British Columbia CANADA

\section{Friday, July 14, 2006}

\begin{tabular}{|c|c|c|}
\hline & Closed Session & \\
\hline 8:00 am & Depart by shuttle to UBC I TRIUMF & Meet in hotel lobby \\
\hline 8:30 am & Breakfast & \\
\hline 9:00 am & Welcome and plans for the meeting & $\begin{array}{l}\text { John Ahearne, Co-chair } \\
\text { Stuart Freedman, Co-chair }\end{array}$ \\
\hline 9:15 am & Discussion of report outline in broad terms & \\
\hline 10:00 am & Break & \\
\hline \multirow[t]{2}{*}{ 10:15 am } & Discussion of candidate science drivers & (All) \\
\hline & OPEN SESSION & \\
\hline $11: 00 \mathrm{am}$ & Perspectives from TRIUMF & $\begin{array}{l}\text { Jean-Michel Poutissou, Associate } \\
\text { Director }\end{array}$ \\
\hline \multirow[t]{2}{*}{ 12:00 pm } & Lunch & \\
\hline & Closed Session & \\
\hline \multirow[t]{5}{*}{$1: 00 \mathrm{pm}$} & Filling in the Report Outline (60 min. each) & \\
\hline & Nuclear Structure & $\begin{array}{l}\text { G. Garvey, W. Haxton, R. Casten, W. } \\
\text { Nazarewicz }\end{array}$ \\
\hline & Nuclear Astrophysics & S. Woosley, M. Wiescher, A. Burrows \\
\hline & Fundamental Symmetries & M. Romalis \\
\hline & Broader Impacts \& Applications & S. Libby \\
\hline $5: 00 \mathrm{pm}$ & Discussion of International Context & P. Braun-Munzinger, P. Schmor \\
\hline 5:45 pm & Adjourn & \\
\hline 6:00 pm & Depart by shuttle back to Vancouver and hotel & \\
\hline $7: 15 \mathrm{pm}$ & Committee Dinner (members and invited guests) & (To Be Determined) \\
\hline
\end{tabular}


Saturday, July 15, 2006

\begin{tabular}{|c|c|c|}
\hline & Closed Session & \\
\hline 8:00 am & Depart by shuttle to UBC / TRIUMF & Meet in hotel lobby \\
\hline 8:30 am & Breakfast & \\
\hline 9:00 am & Revisit and review report outline & \\
\hline 10:00 am & Candidate findings and recommendations & \\
\hline 11:00 am & $\begin{array}{l}\text { Plans for preparing the first full draft of the report } \\
\text { Homework assignments } \\
\text { Additional data needed } \\
\text { Schedule of teleconferences, meetings, etc. }\end{array}$ & J. Ahearne, S. Freedman \\
\hline & OPEN SESSION & \\
\hline $12: 00 \mathrm{pm}$ & Lunch & \\
\hline 1:00 pm & Tour of TRIUMF & \\
\hline $2: 00 \mathrm{pm}$ & Adjourn & \\
\hline 2:15 pm & Depart by taxis to airports, hotels & \\
\hline
\end{tabular}




\title{
Scientific Opportunities with a Rare-Isotope Facility in the United States
}

\author{
Rare-Isotope Science Assessment Committee \\ Board on Physics and Astronomy \\ Division on Engineering and Physical Sciences
}

NATIONAL RESEARCH COUNCIL
OF THE NATIONAL ACADEMIES

THE NATIONAL ACADEMIES PRESS

Washington, D.C.

www.nap.edu 


\section{RARE-ISOTOPE SCIENCE ASSESSMENT COMMITTEE}

JOHN F. AHEARNE, Sigma Xi and Duke University, Co-Chair

STUART J. FREEDMAN, University of California at Berkeley, Co-Chair

RICARDO ALARCON, Arizona State University

PETER BRAUN-MUNZINGER, GSI

ADAM S. BURROWS, University of Arizona

RICHARD F. CASTEN, Yale University

YANGLAI CHO, Argonne National Laboratory (retired)*

GERALD T. GARVEY, Los Alamos National Laboratory

WICK C. HAXTON, University of Washington

ROBERT L. JAFFE, Massachusetts Institute of Technology

NOEMIE B. KOLLER, Rutgers University

STEPHEN B. LIBBY, Lawrence Livermore National Laboratory

SHOJI NAGAMIYA, Japan Proton Accelerator Research Complex

WITOLD NAZAREWICZ, University of Tennessee

MICHAEL ROMALIS, Princeton University

PAUL SCHMOR, TRIUMF

MICHAEL C.F. WIESCHER, University of Notre Dame

STANFORD E. WOOSLEY, University of California at Santa Cruz

*Unable to participate because of illness

Staff

DONALD C. SHAPERO, Board Director

TIMOTHY I. MEYER, Senior Program Officer

DAVID B. LANG, Research Associate

PAMELA LEWIS, Program Associate

PHILLIP D. LONG, Senior Program Assistant

VAN AN, Financial Associate 


\section{Preface}

The Rare-isotope Science Assessment Committee (RISAC) was charged by the National Academies' Board on Physics and Astronomy, the Department of Energy, and the National Science Foundation to define the science agenda for a next-generation U.S. Facility for Rareisotope Beams (FRIB); the full charge is reproduced in Appendix A. By design RISAC consists of scientists who work mostly outside the rare-isotope science community. After RISAC had begun its meetings the DOE announced that the scope of what was then understood as the Rareisotope Accelerator (RIA) should be reduced by about a factor of two and there would be no project-engineering definition funding available until 2011.

These developments in facility definition and projected schedule presented the committee with two chief challenges. First, an effort that had started as an analysis of the most compelling intellectual territory addressed by a well-defined facility was transformed into the inverse task. Thus, the committee focused first on the scientific questions of highest importance and then speculated about the technical capabilities that a next-generation facility (FRIB) would need to make progress. Second, with a shift in the anticipated construction start from 2008 to 2011 at the earliest, the committee was forced to guess at not only the scientific developments more than a decade in the future but also the evolving scientific activities of other facilities and nations around the world.

Nevertheless, in response to the DOE announcement and the charge for this study, the committee has focused on articulating the science that could be accomplished at a reduced-scope rareisotope facility, referred to as FRIB or U.S.-FRIB in this report. The committee offers conclusions on the potential impact of such a facility on nuclear structure, nuclear astrophysics, fundamental interactions and various applications, including national security. The charge called for an evaluation of the impact of FRIB on the overall context of nuclear physics both nationally and internationally. Representatives from major regions of the world (Europe/Germany, Japan and Canada) that have planned and operated existing facilities provided the basis for the committee's advice about the international context of FRIB. To avoid the appearance of bias, the committee membership did not include representatives actively participating in the formulation of proposals to build a U.S.-FRIB. However, the committee did hear testimony from members of those groups (in addition to many others). The committee heard presentations from appropriate experts about applications of a FRIB to areas of medical research, stockpile stewardship, and national security. RISAC was not asked to recommend a specific facility or to compare FRIB with other U.S. initiatives in nuclear science. Furthermore, RISAC was not asked to provide overall guidance on how the United States might most effectively leverage its investments in nuclear science as part of a global program.

The committee thanks the speakers who made formal presentations at each of the meetings; their presentations and the ensuing discussions were extremely informative and had a significant impact on the committee's deliberations. And in general, the committee acknowledges the extra work required to prepare remarks addressing the broad spectrum of expertise on the committee. The committee also thanks the BPA staff (Donald Shapero, Timothy Meyer, and Phillip Long) for their guidance and assistance throughout this process.

On a more personal note, we would also like to extend special thanks and appreciation to RISAC member Gerry Garvey, for his help in skillfully weaving together the views of the committee into 
a consistent whole and in responding to the reviews, which were particularly thoughtful and helpful in refining the report.

John F. Ahearne, Co-Chair

Rare-isotope Science Assessment Committee
Stuart J. Freedman, Co-Chair 


\section{Executive Summary}

Nuclear structure physics aims to describe nuclei as collections of neutrons and protons. Nuclear structure is the traditional core of nuclear science and it has been able to describe a broad range of phenomena from normal nuclei to neutron stars. The understanding of nuclei in this regime provides critical support for important research in nuclear astrophysics and for efforts to exploit nuclei as laboratories for exploring fundamental symmetries.

More than a decade ago the U.S. nuclear structure and nuclear astrophysics communities proposed that a new rare-isotope accelerator be built in the United States. Such a facility would produce a wide variety of high quality beams of unstable isotopes at unprecedented intensities. It would enable a new class of experiments to elucidate the structure of exotic, unstable nuclei to complement the studies of stable nuclei that have been the primary focus of nuclear physics in the past century. A facility with this capability could also provide critical information on the very unstable nuclei that must be understood in order to explain nuclear abundances observed in the universe. This facility would also produce large samples of specific isotopes that could enable a new class of experiments to study fundamental symmetries. A series of studies by the joint NSFDOE Nuclear Science Advisory Committee (NSAC) have supported the need for such a facility, initially termed the Rare Isotope Accelerator (RIA).

To obtain an independent scientific assessment, the National Academies convened the RareIsotope Science Assessment Committee (RISAC). The committee was charged by the Department of Energy and the National Science Foundation to define the science agenda for a next-generation U.S. Facility for Rare-isotope Beams (FRIB). RISAC members included several experts in rare-isotope science, but the committee consisted largely of scientists from outside the rare-isotope science community; it also had members from Canada, Europe, and Asia. Soon after RISAC was formed, the DOE announced that the budget of what was then understood as RIA would be reduced by about a factor of two. In response to this announcement and the charge, the committee has focused on articulating the science that could be accomplished at a rare-isotope facility of reduced scope, referred to as FRIB or U.S.-FRIB in this report. The charge also directed the committee to evaluate the scientific impact of a FRIB in the overall context of the national and international nuclear physics programs.

The committee heard presentations about applications of a FRIB for nuclear physics studies and also to areas of medical research and stockpile stewardship. RISAC was not asked to give advice on whether a facility should be constructed or to compare the relative merits of various possibilities. For its analysis, the committee interpreted U.S.-FRIB as a general-purpose rareisotope production facility with a cost about half that of the earlier RIA concept. To better understand the potential impact on the scientific agenda of such a cost reduction, the committee heard views from some of the proponents of a US-FRIB in a public meeting; these individuals gave the committee their views on production techniques and beam intensities that they judged to be technically feasible. The primary tradeoff indicated in these presentations was a modest reduction in the quantity and diversity of possible isotopes and a significant reduction in the multi-user aspects of the facility.

In developing its conclusions regarding a FRIB, the committee took into account the worldwide portfolio and the likely time frame in which a FRIB facility might begin operations (2016, according to current DOE plans). Despite the uncertainty inherent in predicting what will be the 
important scientific questions in the far future, a powerful new rare-isotope facility could resolve scientific issues of clear importance. Arguments from the groups that have conducted the research and development for FRIB convinced the committee that most of the major technical issues are well in hand. The committee concluded that the case for a next-generation, radioactive beam facility of the type embodied in the U.S.-FRIB concept represents a unique opportunity to explore the nature of nuclei under conditions that only exist otherwise in supernovas and to develop a more quantitatively robust characterization of nuclear structure by exploring new forms of nuclear matter.

A rare-isotope facility produces beams of unstable atomic nuclei for direct study or can use them in subsequent reactions to produce even more exotic nuclear species. Thus, a FRIB could impact the study of the origin of the elements and the evolution of the cosmos as well as the Standard Model of elementary particle physics with groundbreaking research on nuclei far from stability. The committee identified several key science drivers:

- Nuclear structure. A FRIB would offer a laboratory for exploring the limits of nuclear existence and identifying new phenomena, with the possibility that a more broadly applicable theory of nuclei will emerge. FRIB would investigate new forms of nuclear matter such as the large neutron excesses occurring in nuclei near the neutron drip line, thus offering the only laboratory access to matter made essentially of pure neutrons; a FRIB might lead to breakthroughs in the ability to fabricate the super-heavy elements with larger neutron numbers that are expected to exhibit unusual stability in spite of huge electrostatic repulsion.

- Nuclear astrophysics. A FRIB would lead to a better understanding of key issues by creating exotic nuclei that, until now, have existed only in nature's most spectacular explosion, the supernova. A FRIB would offer new glimpses into the origin of the elements, which are produced mostly in processes very far from nuclear stability and which are barely within reach of present facilities. A FRIB would also probe properties of nuclear matter important to theories of neutron-star crusts.

- Fundamental symmetries of nature. Experiments addressing questions of the fundamental symmetries of nature will similarly be conducted at a FRIB through the creation and study of certain exotic isotopes. These nuclei could enable important experiments on basic interactions because aspects of their structure greatly magnify the size of the symmetry-breaking processes being probed. For example, a possible explanation for the observed asymmetry between matter and anti-matter in the universe could be studied by searching for a permanent electric dipole moment larger than Standard Model predictions in heavy radioactive nuclei.

The committee concludes that nuclear structure and nuclear astrophysics constitute a vital component of the nuclear science portfolio in the United States. Moreover, nuclear-structurerelated research provides the scientific basis for important advances in medical research, national security, energy production, and industrial processing. Historically, scientific and technological developments in nuclear science have had extremely broad impact, e.g., nuclear magnetic resonance imaging and the fabrication of more robust electronics. Failure to pursue a U.S.-FRIB would likely lead to a forfeiture of U.S. leadership in nuclear-structure-related physics and would curtail the training of future U.S. nuclear scientists.

The committee concluded that a U.S. facility for rare-isotope beams of the kind described to the committee would be complementary to existing and planned international efforts, particularly if based on a heavy-ion linear accelerator. With such a facility, the United States would be a partner among equals in the exploration of the world-leading scientific thrusts listed above. 
The committee concluded that the science addressed by a rare-isotope facility, most likely based on a heavy-ion driver using a linear accelerator, should be a high priority for the United States. The facility for rare-isotope beams envisaged for the United States would provide capabilities unmatched elsewhere that would help to provide answers to the key science topics outlined above. 


\section{Chicago Oribune}

- ONIINE EDITION-

http://www. chicagotribune.com/business/chi-0612090044dec09,0,4653906.story? coll=chi-business-hed

\section{Isotope project back on track}

\section{Argonne gears up to prepare its case}

By Jon Van

Advertisement

Tribune staff reporter

December 9, 2006

The federal government is reviving plans to build a $\$ 500$ million rare isotope accelerator that scientists at the University of Chicago and Argonne National Laboratory hope to bring to Illinois.

A report released Friday by the influential National Academies of Science supports the notion and a task force organized by the government met in Chicago Friday to discuss how such a project might proceed.

"The real news today is that a project everyone thought was dead is really back on track again," said Michael Turner, Argonne chief scientist.

"Argonne will prepare a great case for building the facility here."

For more than a decade, nuclear physicists have argued the country needs to build a machine that creates unstable atomic forms called isotopes that normally are only seen in exotic locales, such as exploding stars. Isotopes already play major roles in medical diagnosis and treatment, and creating new ones is bound to expand that role, scientists contend.

Such isotopes should be valuable in several aspects of science, as well as bolster interest from Homeland Security in the area of tracing the origin of nuclear explosive materials, for example.

Since 1999, the Department of Energy has spent millions studying the possibility of building a rare isotope accelerator, and two years ago, the project looked like it would proceed. At the last minute, the Bush administration balked at its billion-dollar price tag and sidelined the project.

Energy department officials ordered scientists to scale back their proposal to the $\$ 500$ million range and asked the National Research Council, a nongovernment, non-partisan organization, to assess the value of the science involved. Friday's report, written primarily by scientists outside the nuclear physics field, supported the project.

The report noted that nuclear physics has "had extremely broad impact" on science research and technology. It said failure to build the new machine "would likely lead to forfeiture of U.S. leadership in 
nuclear-structure related physics and would curtail the training of future U.S. nuclear scientists."

When the rare isotope accelerator was first proposed, its backers were primarily nuclear scientists, said Turner, who formerly worked with the National Science Foundation, a federal agency. Without support from the broader science community, federal authorities were reluctant to endorse such a big project. Now that the National Research Council, an affiliate of the National Science Academies, has expressed support, the project has the broad backing needed to snag federal funding, Turner said.

The proposal under consideration "would complement nuclear research machines being built in other countries," said Stuart Freedman, a University of California at Berkeley professor and co-chairman of the report committee.

Freedman acknowledged it's unlikely the United States would willingly forfeit its leading position in nuclear science. Under the Department of Energy's current timetable, construction of the accelerator would begin by 2011 , and the machine would start operating by 2016 .

Argonne and the University of Chicago have plans for a new facility that would be built as an extension of the ATLAS accelerator already operating on the Argonne campus, said Turner.

Researchers from Argonne and Fermilab are collaborating to advance accelerator science in hopes of landing another proposed facility, the International Linear Collider, Turner noted. That collaboration should also bolster the area's case for locating the rare isotope machine here, he said.

Before the Rare Isotope Accelerator was put on hold two years ago, Gov. Rod Blagojevich and the state's congressional delegation joined ranks to bring the facility to Illinois. Former Gov. James Thompson and William Daley, former Clinton-era Cabinet member, signed on to head the Illinois lobbying effort.

While cutting the construction budget in half is a setback, the rare isotope machine would still be a tremendous scientific prize for the region as well as an economic enhancement, said Robert Rosner, Argonne's director.

"In the last five years, we've seen many advances in accelerator technology," said Rosner. "Cutting the budget in half doesn't mean we'll only get half as much value from the accelerator. The research and development money already spent basically has gotten us to a better design now than what was originally proposed."

If the rare isotope project goes ahead as expected, the Department of Energy will likely issue a request for proposals within two years and make a decision as to where the machine will be built, Turner said.

jvan@tribune.com

Copyright $\odot$ 2006, Chicago Tribune 


\section{NEWSFOCUS}

Often he is asked what he has done with the roughly $\$ 350,000$ in Nobel Prize money, an enormous sum in a country where experienced researchers are being promised 30,000 rubles (\$1150) a month by 2008 . He says that he has put the money away for the college educations of his two great-grandchildren, a twin boy and girl living in Princeton, New Jersey.

He sold his country house to help pay for medical treatment and likens his fate to that of two great Soviet physicists, Igor Y. Tamm and Lev D. Landau, both Nobel laureates with whom he worked. (Like Tamm, Ginzburg was recruited to help design the first Soviet nuclear bombs, but by a stroke of luck, he says in his Nobel autobiography, his low security rating kept him in Moscow, away from the Arzamas-16 military site.) Although he is proud to have followed in the footsteps of Tamm and Landau as a physicist, he says he is reluctant to be following "their path [to the grave]." He recounts their deaths in an essay on the Web site of a magazine for which he is editor, Uspekhi Fiziki, or Advances in Physics, which has been in existence since 1918

Tamm, who suffered from amyotrophic lateral sclerosis, or Lou Gehrig's disease, used to say that he was attached to a respirator like "a bug on a pin" in a specimen case. Landau died over the course of 6 years after sustaining painful injuries in a car accident. Ginzburg, saying he has a low tolerance for pain, recently laid bare his wishes in an essay titled, "On the Right to Die." "From the very beginning of my illness, I have dreamed about death, but, of course, a painless death," he writes.

He published the piece online in a relatively obscure publication, he says, to avoid being accused of encouraging euthanasia, a crime in Russia. "I have done all that I can. Within several months at the end of successful treatment, I most likely will have written, in my [90] years, a mere handful of articles and letters. It is absurd to suffer such long months for that. It brings me to recall the joke that goes, 'Why do you exercise?' The answer: 'To die healthy!'”

Civil society, he says, is not sufficiently developed in Russia to enact a right-to-die law anytime soon. So he continues to write the essays and letters for which he has concluded that life is not worth living.

Increasingly, he has been publishing interviews and essays in the magazine Zdravy Smysl, or Common Sense - something that he says is missing from public discourse in his country. "What else can I do?" he says. "For now, living is in the cards."

-BRYON MACWILLIAMS

Bryon MacWilliams is a writer in Moscow.

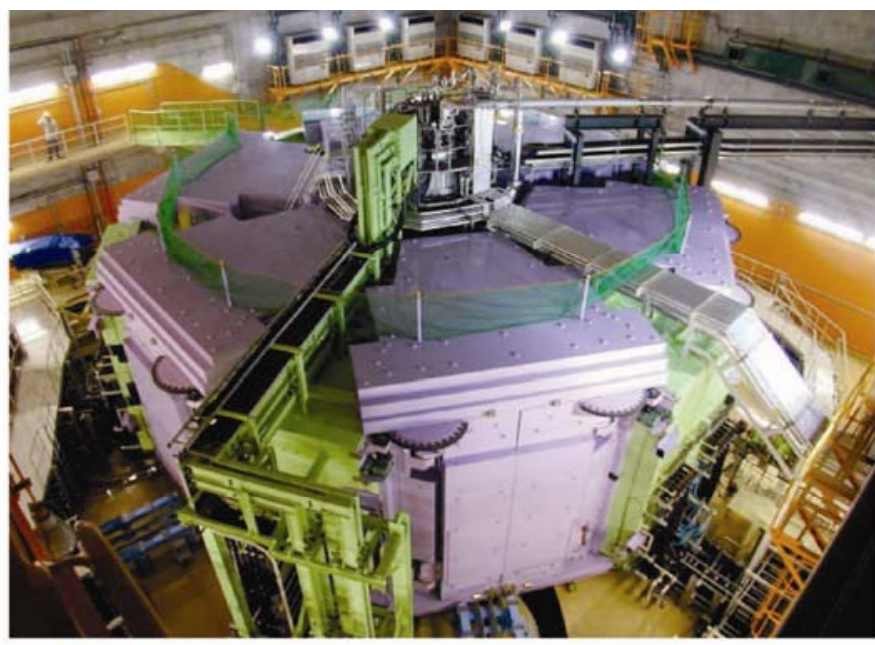

NUCLEAR PHYSICS

\section{Japan Gets Head Start in Race to Build Exotic Isotope Accelerators}

A new facility begins to explore the structure of the nucleus as Europe awaits two machines and the United States revises its plans

WAKO, JAPAN, AND ROSEMONT, ILLINOISSometime this month, a warning siren will clear personnel out of the bowels of a massive concrete building in Wako, a city just east of Tokyo. Then, the world's most powerful cyclotron will propel a stream of uranium ions at a carbon target. The resulting smashup will produce radioactive nuclei that have never existed outside a supernova. Such fleeting exotic bits of matter should help unify a fragmented theory of the nucleus, reveal the origins of the heavier elements, and provide clues to why the universe contains so much more matter than antimatter.

Data from the $\$ 380$ million Radioactive Isotope Beam Factory (RIBF) at the Institute of Physical and Chemical Research (RIKEN) in Wako "will allow us to form a new framework for nuclear physics," says Hiroyoshi Sakurai, chief nuclear physicist at RIKEN's Nishina Center for Accelerator-Based Science, which built and will operate the machine. Richard Casten, a nuclear physicist at Yale University, agrees that knowledge sifted from the atomic shards "will be transformational in our understanding of nuclei."

But Japanese physicists aren't the only ones staking a claim to this fertile turf. RIBF is the first in a new generation of exotic isotope accelerators. Researchers in Germany and France hope to have machines ready to power up in 2010 and 2011 , respectively.
Meanwhile, a U.S. National Research Council (NRC) report released last week makes the case for building the most powerful machine of all. U.S. researchers hope the report will jump-start a project, once known as the Rare Isotope Accelerator (RIA), that stalled last year after the U.S. Department of Energy (DOE) ordered researchers to cut in half the projected \$1 billion cost. "This report helps get the project unstuck by more clearly defining the science that can be done with it and the international situation," says Michael Turner, a cosmologist at the University of Chicago and chief scientist at DOE's Argonne National Laboratory in Illinois, one of two institutions vying for the machine.

Accounting for more than $99.9 \%$ of an atom's mass and less than a billionth of its volume, the nucleus is a knot of protons and neutrons. Nature provides 260 stable nuclei, and researchers have glimpsed 10 times that number of unstable ones. But machines that produce even more would provide new insights into the structure of the nucleus.

For example, since the 1940 s, physicists have known that nuclei with certain "magic" numbers of protons or neutrons appear to be more stable than might otherwise be expected. However, recent findings suggest that the known magic numbers $-2,8,20,28$, 50,82 , and 126 - may not apply to nuclei with an extreme excess or deficiency of 


\section{NEWSFOCUS}

Revving up. Japan's new exotic isotope accelerator should come on line within weeks.

neutrons, says Takaharu Otsuka, a theoretical physicist at the University of Tokyo. An exotic isotope accelerator could search for new magic numbers for highly unstable nuclei and help physicists develop a more comprehensive theory of the nucleus.

Experiments at RIBF will also allow researchers to "take on the challenge" of elucidating stellar processes, says Yasushige Yano, head of the Nishina Center. Scientists believe that half elements heavier than iron are created somewhere within supernovae by a phenomenon known as the R-process, in which nuclei become bloated with neutrons. The resulting neutron-rich nuclei then decay into the familiar stable elements. But physicists don't know precisely how, or even where, the R-process takes place. Studying fleeting neutron-laden nuclei in the lab should help remedy that situation, says Otsuka.

An exotic isotope accelerator might even help explain why the universe is rich in matter and essentially devoid of antimatter. Physicists believe that the imbalance emerged in the infant universe thanks in part to a slight asymmetry between matter and antimatter known as charge-parity $(\mathrm{CP})$ violation, which has been observed only in two types of exotic particles called mesons. According to the standard model of particle physics, such asymmetry could be reflected in the properties of certain exotic nuclei, such as the distribution of electric charge within them. So those nuclei might reveal other sources of $\mathrm{CP}$ violation to probe one of the larger mysteries in the cosmos.

To pursue such goals, RIBF links an existing linear accelerator, or linac, and cyclotron with two new conventional cyclotrons and a superconducting ring cyclotron that

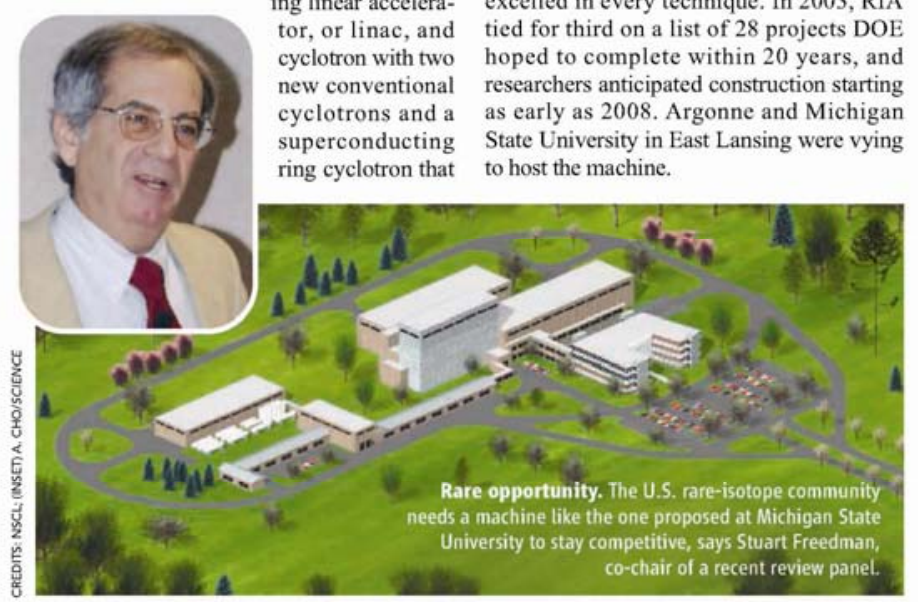
nuclei up to $70 \%$ of light speed. The heavy nuclei will blast through a target of lighter ones and be ripped apart, like a car crashing into a steel post - a process called in-flight fragmentation. The exotic nuclei will be sorted into secondary beams and analyzed or smashed into still other nuclei.

But some of the science may have to wait for more funding. Although the beamline is ready, RIKEN lacks money for instrumentation and experiments. Some projects will start next year, but more complete instrumentation won't be in place until 2008, says Sakurai.

Still, that timetable gives RIKEN a big head start on the competition. Researchers at France's heavy-ion lab, GANIL in Caen, are working on SPIRAL2, a linac that will also produce exotic isotopes by in-flight fragmentation. SPIRAL2 will also smash light nuclei into heavy ones in a solid target to chip the target nuclei apart - a technique known as isotope separation online (ISOL). Meanwhile, researchers at Germany's GSI heavy-ion research center in Darmstadt await a green light to build the sprawling international Facility for Antiproton and Ion Research (FAIR), a synchrotron lab that will produce exotic isotopes, among other things. FAIR will create the nuclei by in-flight fragmentation and will accelerate them to far higher energies. GSI officials are hammering out an agreement with international partners, and construction could start next year.

Researchers in the United States hope that the NRC report will help them get back in the game. In 1999, nuclear physicists proposed using a high-energy, high-throughput linac to create RIA a dream machine that would have excelled in every technique. In 2003, RIA tied for third on a list of 28 projects DOE ction starting host the machine. together will accelerate even the heaviest State University in Fast Lansing were vying
But in February, DOE put the pricey project on hold and asked for something cheaper (Science, 24 February, p. 1082). DOE and the National Science Foundation (NSF) had already requested an NRC review of the science that RIA could do, and the Argonne and Michigan State teams suggested building a shorter linac with half the energy (but twice the beam current) and eliminating experimental stations. Last week, the review committee presented its analysis of the more modest proposal to members of NSF and DOE's Nuclear Science Advisory Committee (NSAC) at a meeting outside Chicago.

Even the smaller-scale machine would be worth building, the committee concluded. "There is a persuasive case for the science that can be done with this machine," says committee co-chair John Ahearne, a physicist with the scientific society Sigma $\mathrm{Xi}$ in Research Triangle Park, North Carolina. That conclusion takes into account the foreseeable competitors, says co-chair Stuart Freedman, an experimental physicist at the University of California, Berkeley, who noted that "without a facility like this, this part of the [U.S. nuclear physics] community likely would not survive."

The report cheered rare-isotope researchers. "It's very positive, very encouraging," says Konrad Gelbke, director of the NSF-funded National Superconducting Cyclotron Laboratory at Michigan State. Donald Geesaman, a physicist at Argonne, says the report provides "validation of the importance of the science from a broader community" than just exotic-isotope researchers. Researchers now hope construction can begin in 2011 for a tart-up in 2016.

Physicists still have a long way to go to transform their idea into a machine, however. First up is a design for the vaguely defined facility, Unlike RIA, the new machine won' do it all. Argonne researchers favor the ISOL approach, whereas Michigan State physicists favor in-flight fragmentation. Both groups would also pursue a novel scheme called reacceleration, catching isotopes in a tank of gas and then feeding them into a second accelerator. This spring, an NSAC subcommittee will weigh in on the matter.

Then there's the question of finding $\$ 500$ million to pay for the machine. Last year, DOE submitted to Congress a 5-year plan "that involves growth in the bottom line of the Office of Science, and this [facility] is part of the plan," says Dennis Kovar, director of the DOE nuclear physics program. Whether the new Congress will go along, however, remains to be seen.

-DENNIS NORMILE AND ADRIAN CHO

Published by AAAS 